\title{
Oxidation of the albumin thiol to sulfenic acid and its implications in the intravascular compartment
}

\author{
L. Turell ${ }^{1,2,3}$, S. Carballal ${ }^{1,3,4}$, H. Botti ${ }^{3,5}$, R. Radi ${ }^{3,4}$ and B. Alvarez $z^{1,3}$ \\ ${ }^{1}$ Laboratorio de Enzimología, ${ }^{2}$ Laboratorio de Fisicoquímica Biológica, Facultad de Ciencias, ${ }^{3}$ Center for \\ Free Radical and Biomedical Research, ${ }^{4}$ Departamento de Bioquímica, Facultad de Medicina, \\ Universidad de la República, Montevideo, Uruguay \\ ${ }^{5}$ Protein Crystallography Unit, Pasteur Institute of Montevideo, Montevideo, Uruguay
}

Correspondence to: B. Alvarez, Laboratorio de Enzimología, Facultad de Ciencias, Iguá 4225, 11400

Montevideo, Uruguay

Fax: +598-2-525-0749. E-mail: beatriz.alvarez@fcien.edu.uy

\begin{abstract}
Human serum albumin (HSA) is the most abundant protein in the intravascular compartment. It possesses a single thiol, Cys34, which constitutes $\sim 80 \%$ of the total thiols in plasma. This thiol is able to scavenge plasma oxidants. A central intermediate in this potential antioxidant activity of human serum albumin is sulfenic acid (HSA-SOH). Work from our laboratories has demonstrated the formation of a relatively stable sulfenic acid in albumin through complementary spectrophotometric and mass spectrometric approaches. Recently, we have been able to obtain quantitative data that allowed us to measure the rate constants of sulfenic acid reactions with molecules of analytical and biological interest. Kinetic considerations led us to conclude that the most likely fate for sulfenic acid formed in the plasma environment is the reaction with low molecular weight thiols to form mixed disulfides, a reversible modification that is actually observed in $\sim 25 \%$ of circulating albumin. Another possible fate for sulfenic acid is further oxidation to sulfinic and sulfonic acids. These irreversible modifications are also detected in the circulation. Oxidized forms of albumin are increased in different pathophysiological conditions and sulfenic acid lies in a mechanistic junction, relating oxidizing species to final thiol oxidation products.
\end{abstract}

Key words: Thiol; Sulfhydryl; Albumin; Sulfenic acid; Mixed disulfides; Plasma

Research supported by grants from Programa de Desarrollo Tecnológico-II (Ministry of Education and Culture, Uruguay), Philip Morris USA Inc. and Philip Morris International, the International Centre of Genetic Engineering and Biotechnology, and the Howard Hughes Medical Institute. L. Turell and H. Botti were supported by fellowships from PEDECIBA-ANII (Uruguay). R. Radi is a Howard Hughes International Research Scholar.

Received September 30, 2008. Accepted February 5, 2009

\section{Introduction}

Oxidative stress is often defined as an imbalance of prooxidants and antioxidants (1). Increasing evidence shows that oxidizing species play a central role in signal transduction under physiological and pathophysiological conditions, leading to new proposals for the definition of oxidative stress in terms of disruption of redox signaling and control (2).

Oxidizing species potentially react with a large group of biomolecules, including nucleic acids and lipids. However, due to their higher concentration in tissues, cells and fluids, proteins are preferential targets (3). Within proteins, cysteine can be oxidized by a wide spectrum of radical and non-radical species, usually at rates several orders of magnitude faster than other amino acids. In the last decade it has been recognized that cysteine oxidative modifications, far from constituting simple scavenging pathways, are involved in redox sensing, activation, catalysis, switching, and cellular signaling (4). Among the different modifications, sulfenic acid is receiving increased interest since it has been identified in a growing list of proteins 
where it serves diverse functions.

In this critical minireview, we describe the properties of the main thiol in the plasma compartment, human serum albumin (HSA-SH), and its oxidation to sulfenic acid (HSA$\mathrm{SOH})$. We propose that HSA-SOH is a central intermediate that can either lead to the formation of reversible mixed disulfides or irreversible higher oxidation states, and we analyze the information obtained by our group and others in the context of the thiol status in the plasma compartment.

\section{Human serum albumin}

Albumin is the most abundant protein in the intravascular space. At a concentration of $\sim 43 \mathrm{~g} / \mathrm{L}(\sim 0.6 \mathrm{mM}), \mathrm{HSA}$ constitutes about $60 \%$ of total plasma protein. It has a molecular mass of $66 \mathrm{kDa}$ and contains, among its 585 amino acids, 6 methionines, 18 tyrosines, 1 tryptophan, 17 disulfide bridges and only one free cysteine, Cys34, which is in the reduced state (HSA-SH) in $\sim 70 \%$ of the HSA molecules. Native albumin is not glycosylated, has an isoionic point of 5.2 and $\sim 19$ negative charges at $\mathrm{pH} 7.4$ (5).

The crystal structure of HSA has already been solved $(6,7)$. It is a monomeric heart-shaped protein, with $67 \%$ of $\alpha$ helixes and no $\beta$ sheets. It has three homologous domains, each containing two subdomains, with common structural features. The only thiol, Cys34, lies in a $9.5 \AA$

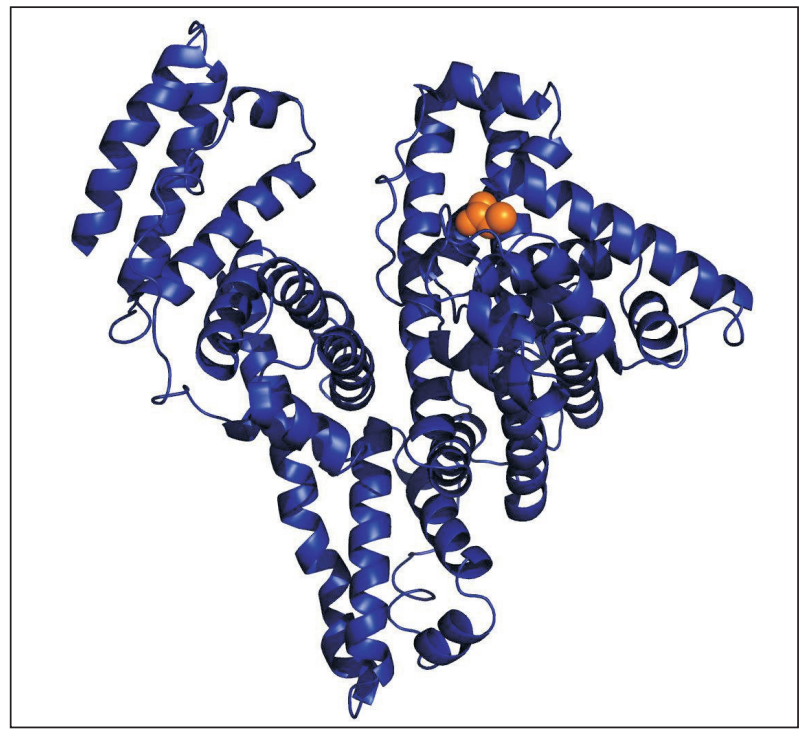

Figure 1. Three-dimensional structure of human serum albumin. Cysteine 34 is shown in orange. Atomic coordinates were downloaded from the Protein Data Bank, accession code 1AO6 (7). The figure was prepared using PyMOL v0.99 (8). cleft, close to the three polar groups of Asp38, His39 and Tyr84 (Figure 1).

Albumin is synthesized in the liver and immediately secreted into the bloodstream. During the 27 days between its birth and death, it makes $\sim 15,000$ trips around the circulation. In addition, it can transfer to the extravascular space and return to the plasma compartment each $\sim 23$ $\mathrm{h}$. This determines that, although albumin is usually seen as a plasma protein, a very important fraction ( $>50 \%)$ is localized extravascularly, mainly in skin and muscle. Albumin is assimilated and degraded more rapidly if it is denatured or altered (5).

Albumin has fundamental roles in the maintenance of colloid osmotic pressure as well as in the binding and transport of ligands such as free fatty acids, hormones and drugs. It also has an antioxidant role, mostly attributed to the cysteine thiol and its ability to react with oxidizing species. In addition, other protective antioxidant properties of albumin include the sequestration of prooxidant molecules and redox active metals as well as the binding of potential antioxidants such as bilirubin. Furthermore, albumin has been proposed to have thioredoxin-dependent lipid hydroperoxide reductase activity in vitro, due to the disulfide between Cys392 and Cys438 (9). Last, albumin has protective effects on the endothelium. For example, it can inhibit the binding of polymorphonuclear leukocytes to cultured endothelial cells (10).

\section{Reactivity of the albumin thiol}

The albumin thiol reacts with hydrogen peroxide $\left(\mathrm{H}_{2} \mathrm{O}_{2}\right)$ and peroxynitrite $\left(\mathrm{ONOO}^{-}\right)$with rate constants of 2.2-2.7 and $3.8 \times 10^{3} \mathrm{M}^{-1} \mathrm{~s}^{-1}$, respectively, at $\mathrm{pH} 7.4$ and $37^{\circ} \mathrm{C}$ (1113). These values are similar to free cysteine and glutathione. Nevertheless, the reactivity of HSA-SH presents additional levels of complexity. According to the model of Christodoulou et al. $(14,15)$, the Cys34 thiol exists in two conformations, and the reduced thiol predominates in a buried conformation that shifts to an exposed one upon oxidation. In addition, the two close groups of His39 and Tyr84 affect the reactivity of the thiol (16). Also, HSA presents $\mathrm{pH}$-dependent structural transitions that impact on thiol reactivity (17). Not surprisingly then, the acidity constant value $\left(\mathrm{pK}_{\mathrm{A}}\right)$ of the albumin thiol remains controversial. This sensitivity of the thiol to protein conformation is also revealed by the fact that its reactivity is affected by the presence of ligands. For example, fatty acids, which bind to sites relatively distant from Cys34, induce conformational changes at the thiol site and increase the reactivity of the thiol towards disulfides $(18,19)$.

Although HSA-SH does not react particularly fast with 
oxidants, it can still be considered to be an important plasma scavenger due to its very high concentration (0.4$0.5 \mathrm{mM}$ ). In the case of hydrogen peroxide, another possible target is glutathione peroxidase 3 , which, at a concentration of $175 \mathrm{nM}$, reacts with a rate constant of $1.8 \mathrm{x}$ $10^{8} \mathrm{M}^{-1} \mathrm{~s}^{-1}(20,21)$. However, the scarcity of glutathione in plasma questions its significance in vivo. In the case of peroxynitrite, the reaction with carbon dioxide $\left(4.6 \times 10^{4}\right.$ $\left.\mathrm{M}^{-1} \mathrm{~s}^{-1}, 1.3 \mathrm{mM}\right)(22)$ is a preferential decay pathway. This reaction leads to the formation of carbonate radical anion and nitrogen dioxide, which in turn react with $\mathrm{HSA}-\mathrm{SH}$ $(11,23)$.

\section{Heterogeneity of the albumin thiol}

Albumin isolated from blood is heterogeneous with respect to its Cys34 oxidation state $(24,25)$. The heterogeneity of albumin can be revealed, among other techniques, by anion exchange-hydrophobic interaction chromatography (26) and mass spectrometry $(27,28)$. The fraction containing the reduced thiol is known as mercaptalbumin and comprises $\sim 70 \%$ of total albumin, whereas the nonmercaptalbumin fraction consists mainly of mixed disulfides between Cys34 and low molecular weight thiols, mostly cysteine (25\%) (27). A minor fraction ( 1\%) also exists where the thiol is oxidized to higher oxidation states including sulfinic and sulfonic acids, not reducible with reagents such as dithiothreitol. A small amount of dimers and higher oligomers that increase with purification and storage can also be observed. Last, nitroso-albumin (HSA$\mathrm{SNO}$ ) has also been detected at concentrations of $<0.2 \mu \mathrm{M}$ and could constitute a reservoir of nitric oxide $(29,30)$.

\section{Thiol status in the intravascular compartment}

Table 1 shows data from the literature regarding the concentration of thiols and related species in the circulation. A close look at the numbers allows one to reach several conclusions. First, the most abundant reduced thiols are protein thiols, mainly albumin, while the concentration of non-protein reduced thiols is only $15-20 \mu \mathrm{M}$. Second, in contrast to the intracellular situation, characterized by high thiol/disulfide ratios, the extracellular plasma compartment is relatively oxidizing and has thiol/disulfide ratios lower than 0.1 for cysteine, cysteinylglycine and homocysteine. The exceptions are glutathione (thiol/disulfide ratio $\sim 2$ ) and albumin (thiol/disulfide ratio $\sim 3$ ). It is worth noting that the pool of protein-bound thiols corresponds mostly (70-90\%) to albumin mixed disulfides, with only a low percentage of disulfides with other proteins (i.e., globulins) (31). Third, the different thiol/disulfide pairs are clearly not in equilibrium, suggesting that kinetic barriers exist for maintaining their steady-state concentrations. These bottlenecks are not yet completely identified and are likely to involve not only rates of chemical reactions (i.e., thiol disulfide exchange processes) but also rates of transport between compartments.

\section{Formation and properties of sulfenic acid}

The main general reactions of sulfenic acid are depicted in Figure 2. Sulfenic acid is formed mainly after the two-electron oxidation of a thiol with oxidants such as hydrogen peroxide and peroxynitrite. Another possible pathway is the one-electron oxidation to a thiyl radical $\left(R^{*}\right)$ that reacts with oxygen leading to a number of secondary radicals, including peroxyl radical (R-SOO*) and sulfinyl radical (R-SO*), finally yielding sulfenic acid $(32,33)$. An additional route is the base-catalyzed hydrolysis of disulfides (34).

Table 1. Concentration of thiols and derived species in plasma from healthy adult males.

\begin{tabular}{|c|c|c|}
\hline Species & Concentration $(\mu \mathrm{M})$ & References \\
\hline Total albumin & 650 & 5 \\
\hline Protein thiols & 452 & 35 \\
\hline \multicolumn{3}{|l|}{ Cysteine } \\
\hline Total & $202-268$ & $36-38$ \\
\hline Reduced & $8.3-10.7$ & $35-37$ \\
\hline LMW disulfide & $85-122$ & $35-37$ \\
\hline Protein mixed disulfide & $145-176$ & $35-37$ \\
\hline \multicolumn{3}{|l|}{ Cysteinylglycine } \\
\hline Total & $31.8-35.8$ & 36,37 \\
\hline Reduced & $2.6-2.9$ & $35-37$ \\
\hline LMW disulfide & $9.7-13.5$ & $35-37$ \\
\hline Protein mixed disulfide & $12-20$ & $35-37$ \\
\hline \multicolumn{3}{|l|}{ Homocysteine } \\
\hline Total & 8.3-11.9 & $36-38$ \\
\hline Reduced & $0.17-0.32$ & $35-37$ \\
\hline LMW disulfide & $1.9-2.4$ & $35-37$ \\
\hline Protein mixed disulfide & 7.3-10.4 & $35-37$ \\
\hline \multicolumn{3}{|l|}{ Glutathione } \\
\hline Total & $6.2-7.3$ & 36,37 \\
\hline Reduced & $3.3-5.1$ & $35-37$ \\
\hline LMW disulfide & $1.4-3.2$ & $35-37$ \\
\hline Protein mixed disulfide & $0.7-1.9$ & $35-37$ \\
\hline \multicolumn{3}{|l|}{$\gamma$-glutamylcysteine } \\
\hline Total & $3.1-5.4$ & 37,38 \\
\hline Reduced & 0.06 & 37 \\
\hline LMW disulfide & 1.8 & 37 \\
\hline Protein mixed disulfide & 1.2 & 37 \\
\hline
\end{tabular}

LMW = low molecular weight. 
Sulfenic acid exhibits both nucleophilic and electrophilic reactivity. This dual character is revealed by its capacity to self-condensate to a thiosulfinate (RS(O)SR') $(39,40)$. Sulfenic acid can also react with a thiol, providing a mechanism for disulfide formation. Disulfide, of course, can be reduced back to thiol enzymatically and non-enzymatically with thiol reagents. Alternatively, sulfenic acid can be further oxidized to sulfinic $\left(\mathrm{RSO}_{2} \mathrm{H}\right)$ and sulfonic acids $\left(\mathrm{RSO}_{3} \mathrm{H}\right)$, which usually do not react with thiol reagents (40). Moreover, sulfenic acid can also react with an amine leading to the formation of a sulfenamide (RSNHR') (41). This modification can be reduced back to thiol. The formation of cyclic sulfenamide after the reaction of a sulfenic acid with a neighboring amide nitrogen has been reported (42), as well as the formation of a hypervalent sulfur compound (a type of sulfurane) following reaction with a histidine (43).

Thus, sulfenic acid constitutes an intermediate in thiol oxidation pathways. The final outcome of the oxidative process will ultimately depend on whether the sulfenic acid is further oxidized to sulfinic and sulfonic acids, these usually being irreversible processes leading to end products, or whether sulfenic acid reacts with a thiol or an amine leading to a potentially reversible modification. Nevertheless, sulfenic acid can be stabilized by the protein environment, and in several proteins sulfenic acid exists and is stable enough to be detected and even characterized. The main factor accounting for sulfenic acid stabilization is the absence of neighboring thiols, as well as the presence of suitable hydrogen bonding or electrostatic

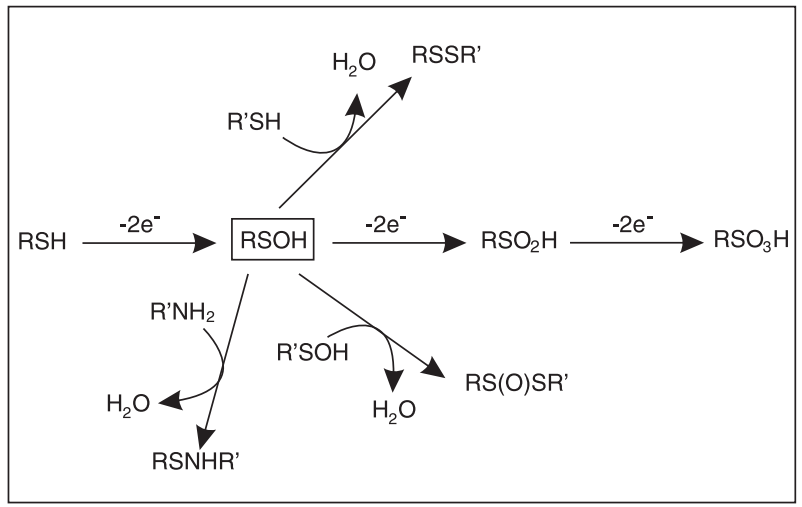

Figure 2. Formation and reactions of sulfenic acid. Thiol (RSH) can be oxidized by two electrons to sulfenic acid (RSOH). In the presence of excess oxidant, sulfenic acid can be further oxidized to sulfinic $\left(\mathrm{RSO}_{2} \mathrm{H}\right)$ and sulfonic $\left(\mathrm{RSO}_{3} \mathrm{H}\right)$ acid. Alternatively, sulfenic acid can react with another thiol to form a disulfide (RSSR'), or with a second sulfenic acid yielding thiosulfinate (RS(O)SR'). Last, sulfenic acid can also react with an amine to form a sulfenamide (RSNHR'). counterparts. These features are present in the albumin molecule.

\section{Detection of sulfenic acid in human serum albumin}

Sulfenic acids do not possess characteristic absorbance or fluorescence properties, and therefore different strategies have been devised to detect them. The electrophilic reagent 7-chloro-4-nitrobenzo-2-oxa-1,3-diazol (NBD-Cl) has been employed to detect sulfenic acid in several proteins based on the different absorbance features of the products formed with the thiol versus the sulfenic acid (44). However, in the case of albumin, sulfenic acid cannot be detected spectrophotometrically with NBD$\mathrm{Cl}$ due to interference from other nucleophilic protein residues $(13,45)$.

Sulfenic acid can also be detected after its reaction with arsenite, since arsenite reduces sulfenic acid back to thiol but does not reduce disulfides. This reagent provided the first evidence that sulfenic acid could be formed in albumin after exposure to oxidizing systems $(46,47)$.

Since there are few electrophilic groups in proteins, the reaction of the sulfur atom of sulfenic acid with nucleophiles is useful for its detection. Thus, dimedone (5,5dimethyl-1,3-cyclohexanedione) selectively derivatizes sulfenic acid yielding a stable thiother, which can be identified by mass spectrometry or by incorporation of a radioactive, fluorescent or biotin tag $(41,48)$. In the case of albumin, the mass spectrometric detection of dimedonetrapped sulfenic acid confirmed that the modification occurred at Cys34 (12).

Despite the fact that there is a growing list of approaches for detecting sulfenic acid in proteins, they are not suitable for obtaining quantitative and kinetic data; hence, information regarding the properties and reactivity of biological sulfenic acid is limited. We have developed a strategy for quantifying albumin sulfenic acid based on the reaction with the yellow thiol thionitrobenzoate (TNB, Figure 3) (13). This thiol has been previously used in end point measurements (49). In the case of albumin, end point measurements can be misleading since the reaction is relatively complex and albumin can non-covalently bind TNB and the disulfide DTNB. Thus, the kinetics of the reaction needs to be considered.

\section{Reactivity of sulfenic acid in albumin}

A careful analysis of the reaction between albumin sulfenic acid and TNB allowed us to perform a comprehensive study of the formation and reactivity of this intermedi- 
ate. We studied its rate of formation after albumin thiol oxidation with hydrogen peroxide and its reactivity with several molecules of analytical or biological interest such as dimedone, sodium arsenite, thiols, amines and other plasma reductants and oxidants (13).

This approach allowed us to rationalize the possible fates of albumin sulfenic acid formed in plasma. Kinetic considerations of rate constant times concentration suggest that its most likely fate is the reaction with low molecular weight thiols to form mixed disulfides, since the rate constants of the reactions with cysteine, glutathione, homocysteine and cysteinylglycine are 21.6, 2.9, 9.3, and 55 $\mathrm{M}^{-1} \mathrm{~s}^{-1}, \mathrm{pH} 7.4,25^{\circ} \mathrm{C}$, so that, at the concentrations present in plasma (Table 1), these thiols are the preferential targets of albumin sulfenic acid. Once the mixed disulfides are formed, further reaction with another thiol can lead to low molecular weight disulfides. Other plasma reductants such as ascorbate and urate do not react with sulfenic acid. Furthermore, electrophoresis has ruled out the formation of albumin disulfide dimers. As for the formation of sulfenamides, the reaction of sulfenic acid with free amino acids was not detectable and the formation of a cyclic sulfenamide cannot occur because the neighboring amide belongs to proline. Another possible fate of sulfenic acid is further oxidation. Indeed, hydrogen peroxide reacts with sulfenic acid with a rate constant of $0.4 \mathrm{M}^{-1} \mathrm{~s}^{-1}$ leading to sulfinic acid.

\section{Implications in pathology}

Plasma values are consistent with our kinetic considerations, since mixed albumin disulfides are found in $25 \%$ of circulating albumin and higher oxidation states have been found in vivo and are related to several pathological conditions. This supports our hypothesis that the sulfenic acid form is a central intermediate in the scavenging activity of the albumin thiol and in the formation of more stable oxidized albumin isoforms such as sulfinic and sulfonic acid. The oxidized forms of albumin are apparently picked up in the circulation since they are not present in albumin secreted from the liver cells (5). Thus, they may constitute

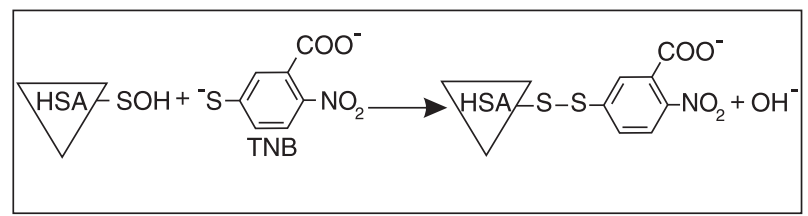

Figure 3. Reaction of albumin sulfenic acid (HSA-SOH) with thionitrobenzoate (TNB).

potential markers of the scavenging activity of the thiol of albumin. In fact, the fraction of oxidized albumin correlates with several pathologies. In patients with different renal diseases the level of oxidized albumin is increased (28, $50,51)$. Recently, a progressive oxidative modification of albumin with increasing severity of liver failure has been reported (52). The fraction of oxidized albumin is also increased in diabetes mellitus (53), disorders of the temporomandibular joint (54), senile cataract (55), and invasive surgery (56). Furthermore, it has been shown that the fraction of oxidized albumin also increases with aging $(26,35)$ and intense exercise $(57)$.

As for the generation of protein mixed disulfides, although it can be interpreted as an indication of oxidative damage in terms of consumption of reduced thiol, this process could function as a protective mechanism, preventing the oxidation of the thiol in albumin to irreversible states such as sulfinic and sulfonic acids.

\section{Conclusions}

The molecular mechanisms that determine the oxidation state of the plasma thiols are only starting to be understood. The sulfenic acid of human serum albumin is a central intermediate in thiol oxidation pathways and lies in a mechanistic junction, linking oxidizing species with final thiol oxidation products.

\section{Acknowledgments}

We thank Drs. Matías Möller, Madia Trujillo and Gerardo Ferrer-Sueta for helpful discussions.

\section{References}

1. Sies H. Oxidative stress. London: Academic Press; 1985.

2. Jones DP. Redefining oxidative stress. Antioxid Redox Signal 2006; 8: 1865-1879.

3. Davies MJ. The oxidative environment and protein damage. Biochim Biophys Acta 2005; 1703: 93-109.

4. Jacob C, Knight I, Winyard PG. Aspects of the biological redox chemistry of cysteine: from simple redox responses to sophisticated signalling pathways. Biol Chem 2006; 387: 1385-1397.

5. Peters T. All about albumin. Biochemistry, genetics and medical applications. London: Academic Press; 1996.

6. Carter DC, He XM, Munson SH, Twigg PD, Gernert KM, 
Broom MB, et al. Three-dimensional structure of human serum albumin. Science 1989; 244: 1195-1198.

7. Sugio S, Kashima A, Mochizuki S, Noda M, Kobayashi K. Crystal structure of human serum albumin at $2.5 \mathrm{~A}$ resolution. Protein Eng 1999; 12: 439-446.

8. Delano WL. DeLano Scientific. http://www.pymol.org

9. Cha MK, Kim IH. Disulfide between Cys392 and Cys438 of human serum albumin is redox-active, which is responsible for the thioredoxin-supported lipid peroxidase activity. Arch Biochem Biophys 2006; 445: 19-25.

10. Lang JD Jr, Figueroa M, Chumley $P$, Aslan M, Hurt J, Tarpey MM, et al. Albumin and hydroxyethyl starch modulate oxidative inflammatory injury to vascular endothelium. Anesthesiology 2004; 100: 51-58.

11. Alvarez B, Ferrer-Sueta G, Freeman BA, Radi R. Kinetics of peroxynitrite reaction with amino acids and human serum albumin. J Biol Chem 1999; 274: 842-848.

12. Carballal S, Radi R, Kirk MC, Barnes S, Freeman BA, Alvarez B. Sulfenic acid formation in human serum albumin by hydrogen peroxide and peroxynitrite. Biochemistry 2003; 42: 9906-9914.

13. Turell L, Botti H, Carballal S, Ferrer-Sueta G, Souza JM, Duran R, et al. Reactivity of sulfenic acid in human serum albumin. Biochemistry 2008; 47: 358-367.

14. Christodoulou J, Sadler PJ, Tucker A. A new structural transition of serum albumin dependent on the state of Cys34. Detection by 1H-NMR spectroscopy. Eur J Biochem 1994; 225: 363-368.

15. Christodoulou J, Sadler PJ, Tucker A. 1 H NMR of albumin in human blood plasma: drug binding and redox reactions at Cys34. FEBS Lett 1995; 376: 1-5.

16. Stewart AJ, Blindauer CA, Berezenko S, Sleep D, Tooth D, Sadler PJ. Role of Tyr84 in controlling the reactivity of Cys34 of human albumin. FEBS J 2005; 272: 353-362.

17. Pedersen $A O$, Jacobsen J. Reactivity of the thiol group in human and bovine albumin at $\mathrm{pH} 3-9$, as measured by exchange with 2,2'-dithiodipyridine. Eur J Biochem 1980; 106: 291-295.

18. Curry S, Brick P, Franks NP. Fatty acid binding to human serum albumin: new insights from crystallographic studies. Biochim Biophys Acta 1999; 1441: 131-140.

19. Gryzunov YA, Arroyo A, Vigne JL, Zhao Q, Tyurin VA, Hubel CA, et al. Binding of fatty acids facilitates oxidation of cysteine-34 and converts copper-albumin complexes from antioxidants to prooxidants. Arch Biochem Biophys 2003; 413: 53-66.

20. Flohe L, Loschen G, Gunzler WA, Eichele E. Glutathione peroxidase, V. The kinetic mechanism. Hoppe Seylers $Z$ Physiol Chem 1972; 353: 987-999.

21. Manta B, Hugo M, Ortiz C, Ferrer-Sueta G, Trujillo M, Denicola $A$. The peroxidase and peroxynitrite reductase activity of human erythrocyte peroxiredoxin 2. Arch Biochem Biophys 2008.

22. Denicola A, Freeman BA, Trujillo M, Radi R. Peroxynitrite reaction with carbon dioxide/bicarbonate: kinetics and influence on peroxynitrite-mediated oxidations. Arch Biochem Biophys 1996; 333: 49-58.

23. Bonini MG, Fernandes DC, Augusto O. Albumin oxidation to diverse radicals by the peroxidase activity of $\mathrm{Cu}, \mathrm{Zn}$-superoxide dismutase in the presence of bicarbonate or nitrite: diffusible radicals produce cysteinyl and solvent-exposed and -unexposed tyrosyl radicals. Biochemistry 2004; 43: 344-351.

24. Janatova J, Fuller JK, Hunter MJ. The heterogeneity of bovine albumin with respect to sulfhydryl and dimer content. J Biol Chem 1968; 243: 3612-3622.

25. Noel JK, Hunter MJ. Bovine mercaptalbumin and nonmercaptalbumin monomers. Interconversions and structural differences. J Biol Chem 1972; 247: 7391-7406.

26. Era S, Hamaguchi T, Sogami M, Kuwata K, Suzuki E, Miura $\mathrm{K}$, et al. Further studies on the resolution of human mercaptand nonmercaptalbumin and on human serum albumin in the elderly by high-performance liquid chromatography. Int J Pept Protein Res 1988; 31: 435-442.

27. Beck JL, Ambahera S, Yong SR, Sheil MM, de Jersey J, Ralph SF. Direct observation of covalent adducts with Cys34 of human serum albumin using mass spectrometry. Anal Biochem 2004; 325: 326-336.

28. Musante L, Bruschi M, Candiano G, Petretto A, Dimasi N, Del Boccio $P$, et al. Characterization of oxidation end product of plasma albumin 'in vivo'. Biochem Biophys Res Commun 2006; 349: 668-673.

29. Tsikas D, Frolich JC. S-nitrosoalbumin plasma levels in health and disease: facts or artifacts? Value of analytical chemistry in nitric oxide clinical research. Circ Res 2002; 90: e39.

30. Rassaf T, Feelisch M, Kelm M. Circulating NO pool: assessment of nitrite and nitroso species in blood and tissues. Free Radic Biol Med 2004; 36: 413-422.

31. Hortin GL, Seam N, Hoehn GT. Bound homocysteine, cysteine, and cysteinylglycine distribution between albumin and globulins. Clin Chem 2006; 52: 2258-2264.

32. Bonini MG, Augusto O. Carbon dioxide stimulates the production of thiyl, sulfinyl, and disulfide radical anion from thiol oxidation by peroxynitrite. J Biol Chem 2001; 276: 97499754.

33. Carballal S, Alvarez B, Turell L, Botti H, Freeman BA, Radi R. Sulfenic acid in human serum albumin. Amino Acids 2007; 32: 543-551.

34. Poole LB, Karplus PA, Claiborne A. Protein sulfenic acids in redox signaling. Annu Rev Pharmacol Toxicol 2004; 44: 325-347.

35. Giustarini D, Dalle-Donne I, Lorenzini S, Milzani A, Rossi R. Age-related influence on thiol, disulfide, and protein-mixed disulfide levels in human plasma. J Gerontol A Biol Sci Med Sci 2006; 61: 1030-1038.

36. Mansoor MA, Svardal AM, Ueland PM. Determination of the in vivo redox status of cysteine, cysteinylglycine, homocysteine, and glutathione in human plasma. Anal Biochem 1992; 200: 218-229.

37. Andersson A, Isaksson A, Brattstrom L, Hultberg B. Homocysteine and other thiols determined in plasma by HPLC and thiol-specific postcolumn derivatization. Clin Chem 1993; 39: 1590-1597.

38. Kleinman WA, Richie JP Jr. Status of glutathione and other thiols and disulfides in human plasma. Biochem Pharmacol 2000; 60: 19-29.

39. Kice J, Cleveland J. Nucleophilic substitution reactions involving sulfenic acids and sulfenyl derivatives. Nucleophileand acid-catalyzed oxygen-18 exchange of phenyl benzenethiolsulfinate. J Am Chem Soc 1973; 95: 104-109.

40. Torchinsky Y. Sulfur in proteins. Oxford: Pergamon Press, 
Ltd: 1981.

41. Allison W. Formation and reactions of sulfenic acids in proteins. Acc Chem Res 1976; 9: 293-299.

42. Salmeen A, Andersen JN, Myers MP, Meng TC, Hinks JA, Tonks NK, et al. Redox regulation of protein tyrosine phosphatase $1 \mathrm{~B}$ involves a sulphenyl-amide intermediate. $\mathrm{Na}$ ture 2003; 423: 769-773.

43. Nakamura T, Yamamoto $T$, Abe M, Matsumura $\mathrm{H}$, Hagihara $\mathrm{Y}$, Goto $\mathrm{T}$, et al. Oxidation of archaeal peroxiredoxin involves a hypervalent sulfur intermediate. Proc Natl Acad Sci U S A 2008; 105: 6238-6242.

44. Ellis HR, Poole LB. Novel application of 7-chloro-4nitrobenzo-2-oxa-1,3-diazole to identify cysteine sulfenic acid in the AhpC component of alkyl hydroperoxide reductase. Biochemistry 1997; 36: 15013-15018.

45. Kratochwil NI, Patriarca M, Parkinson J, Gouldsworthy A, Murdoch $\mathrm{P}$, Sadler $\mathrm{P}$. Surprising reactions of iodo $\mathrm{Pt}(\mathrm{IV})$ and $\mathrm{Pt}$ (II) complexes with human serum albumin: detection of Cys34 sulfenic acid. J Am Chem Soc 1999; 121: 81938203.

46. Radi R, Beckman JS, Bush KM, Freeman BA. Peroxynitrite oxidation of sulfhydryls. The cytotoxic potential of superoxide and nitric oxide. J Biol Chem 1991; 266: 4244-4250.

47. Radi R, Bush KM, Cosgrove TP, Freeman BA. Reaction of xanthine oxidase-derived oxidants with lipid and protein of human plasma. Arch Biochem Biophys 1991; 286: 117125.

48. Poole LB, Klomsiri C, Knaggs SA, Furdui CM, Nelson KJ, Thomas MJ, et al. Fluorescent and affinity-based tools to detect cysteine sulfenic acid formation in proteins. Bioconjug Chem 2007; 18: 2004-2017.

49. Poole LB, Ellis HR. Identification of cysteine sulfenic acid in AhpC of alkyl hydroperoxide reductase. Methods Enzymol
2002; 348: 122-136.

50. Terawaki H, Yoshimura K, Hasegawa T, Matsuyama $Y$, Negawa T, Yamada K, et al. Oxidative stress is enhanced in correlation with renal dysfunction: examination with the redox state of albumin. Kidney Int 2004; 66: 1988-1993.

51. Musante L, Candiano G, Petretto A, Bruschi M, Dimasi N, Caridi G, et al. Active focal segmental glomerulosclerosis is associated with massive oxidation of plasma albumin. J Am Soc Nephrol 2007; 18: 799-810.

52. Oettl K, Stadlbauer V, Petter F, Greilberger J, Putz-Bankuti C, Hallstrom S, et al. Oxidative damage of albumin in advanced liver disease. Biochim Biophys Acta 2008; 1782: 469-473.

53. Suzuki E, Yasuda K, Takeda N, Sakata S, Era S, Kuwata K, et al. Increased oxidized form of human serum albumin in patients with diabetes mellitus. Diabetes Res Clin Pract 1992; 18: 153-158.

54. Tomida M, Ishimaru JI, Murayama K, Kajimoto T, Kurachi $\mathrm{M}$, Era S, et al. Intra-articular oxidative state correlated with the pathogenesis of disorders of the temporomandibular joint. Br J Oral Maxillofac Surg 2004; 42: 405-409.

55. Hayashi T, Era S, Kawai K, Imai H, Nakamura K, Onda E. Observation for redox state of human serum and aqueous humor albumin from patients with senile cataract. Pathophysiology 2000; 6: 237-243.

56. Hayakawa A, Kuwata K, Era S, Sogami M, Shimonaka H, Yamamoto $\mathrm{M}$, et al. Alteration of redox state of human serum albumin in patients under anesthesia and invasive surgery. J Chromatogr B Biomed Sci Appl 1997; 698: 27-33.

57. Imai $\mathrm{H}$, Hayashi $\mathrm{T}$, Negawa $\mathrm{T}$, Nakamura K, Tomida M, Koda K, et al. Strenuous exercise-induced change in redox state of human serum albumin during intensive kendo training. Jpn J Physiol 2002; 52: 135-140. 